\title{
Pattern of dermatoses in Iraqi children
}

M. D. Al-Mendalawi' and J.G. Ibrahim ${ }^{2}$

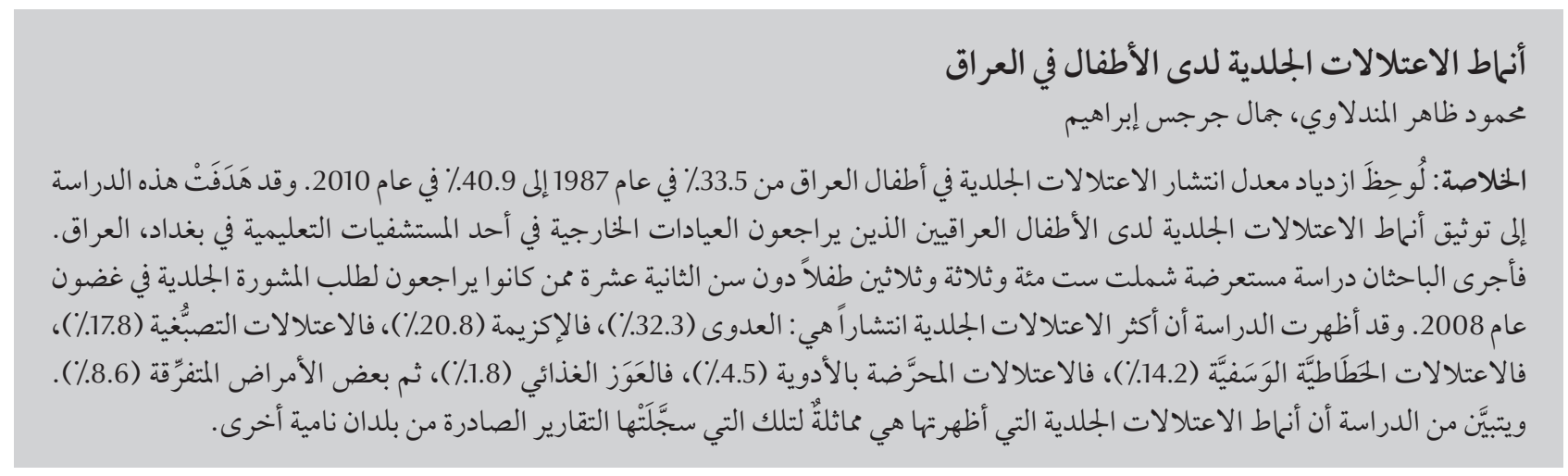

ABSTRACT The prevalence of paediatric dermatoses has risen in Iraq from $33.5 \%$ in 1987 to $40.9 \%$ in 2010 . The objective of this study was to document the pattern of dermatoses in Iraqi children attending the outpatient clinic of a teaching hospital in Baghdad, Iraq. We conducted a cross-sectional study of 663 children under the age of 12 years who attended for dermatological consultation during 2008. The study showed that the prevailing dermatoses were as follow: infectious (32.3\%), eczematous $(20.8 \%)$, pigmentary (17.8\%), papulosquamous (14.2\%), drug-induced (4.5\%), nutritional deficiency (1.8\%) and miscellaneous (8.6\%). The studied patterns of dermatoses were similar to that reported in other developing countries.

\section{Caractéristiques des dermatoses chez des enfants iraquiens}

RÉSUMÉ La prévalence des dermatoses pédiatriques en Iraq est passée de 33,5 \% en 1987 à 40,9 \% en 2010. La présente étude visait à documenter les caractéristiques des dermatoses chez des enfants iraquiens fréquentant un centre de consultation externe d'un hôpital universitaire à Bagdad (Iraq). Nous avons mené une étude transversale auprès de 663 enfants de moins de 12 ans soignés en consultation dermatologique en 2008. L'étude a révélé que les dermatoses prévalentes étaient les suivantes : dermatoses infectieuses (32,3\%), eczémateuses $(20,8 \%)$, pigmentaires $(17,8 \%)$, papulosquameuses $(14,2 \%)$, médicamenteuses $(4,5 \%)$, nutritionnelles dues à des carences $(1,8 \%)$ et dermatoses d'autres origines $(8,6 \%)$. Les caractéristiques des dermatoses étudiées étaient similaires à celles notifiées dans d'autres pays en développement. 


\section{Introduction}

Dermatoses represent an important public health burden, particularly in developing countries, where high prevalence figures $(21 \%-87 \%)$ have been reported [1]. Children present a higher prevalence rate than adults for pyoderma (especially under 5 years of age), certain mycoses (tinea capitis) and, to a lesser extent, scabies. Skin disorders represent one of the main organ-specific reasons for visiting a primary health care centre. Despite the relative paucity of objective data and some methodological restrictions, the main etiological factors in developing countries are factors such as hot and humid climate, low hygiene and poor access to water, high interpersonal contact and household overcrowding and reactions to insect bites and scabies [1]. Apart from the financial burden on families to treat skin diseases in their children [2], late diagnosis and/or poor treatment of certain paediatric dermatoses have a significant impact on sleep pattern, growth potential and quality of life of children and their parents [3].

In Iraq, the prevalence paediatric dermatoses has risen from $33.5 \%$ in 1987 [4] to $40.9 \%$ in 2010 [5]. This could be attributed to a decline in the socioeconomic conditions of most Iraqi people and a general deterioration in services which followed the 1991 Gulf War, economic sanctions and the invasion of Iraq by Allied Forces in 2003, with the accompanying internal conflict. A great deal of research has been conducted on dermatoses in Iraq. However, data about dermatoses among children are lacking. The aim of this study was to identify the pattern of dermatoses in Iraqi children, with the hope that the data will be useful for practising paediatricians and dermatologists.

\section{Methods}

A cross-sectional study was carried out on 663 children under the age of 12 years with various dermatoses who attended the dermatological consultation outpatient clinic at Al-Kindy teaching hospital in Baghdad between 1 July to 31 December 2008. Patients with known chronic dermatoses who came for regular fellow-up were excluded from the study to avoid repeat data.

Diagnoses were made after history taking and clinical examination. The diagnostic criteria listed in Nelson textbook of paediatrics were considered in the clinical diagnosis of the studied dermatoses [6]. Certain laboratory investigations such as direct microscopic examination of skin scrapings with 10\% potassium hydroxide for fungi, fluorescence under wood-light lamp, direct microscopic examination of skin scrapings for scabies, complete blood count, differential white blood cell count and erythrocyte sedimentation rate were performed whenever necessary to confirm diagnosis.

The collected data were analysed and frequencies and percentages tabulated according to diagnosis.

\section{Results}

Of 663 children included over the 6-month period, 374 (56.4\%) were males and 289 (43.6\%) were females. The male to female ratio was 1:0.77. Their age ranged from 1 month to 12 years with a mean age of 5.8 (standard deviation 3.9) years.

Table 1 shows the distribution of various dermatoses by age and sex of the studied patients.

Infectious dermatoses were the preponderant type of dermatosis (214 cases, $32.3 \%)$. Among them, fungal were the most common infections (13.3\%), followed by parasitic (9.8\%), viral (5.1\%) and bacterial (4.1\%). Tinea (5.9\%), pityriasis versicolor (3.8\%) and candidiasis (3.6\%) were the commonly encountered fungal dermatoses. Parasitic dermatoses constituted $(9.8 \%)$ of total infectious dermatoses, notably scabies (4.2\%), pediculosis (3.6\%), and cutaneous leishmaniasis (2.0\%). Viral dermatoses formed $5.1 \%$ of the total and included warts (2.1\%), molluscum contagiosum (1.5\%), herpetic stomatitis (1.2\%) and chickenpox $(0.3 \%)$. Bacterial dermatoses represented the least $(4.1 \%)$ and included impetigo (2.3\%), boil (1.2\%) and cellulitis (2.7\%)

Eczematous dermatoses were the second most common category (145 cases, 21.9\%). Atopic dermatitis was the preponderant type (14.5\%). Most patients with atopic dermatitis were below 8 years of age with the peak incidence in the $0-3$ year age group. Facial and flexural involvements were mainly observed in the studied patients. Other less common eczematous dermatoses were contact dermatitis (4.7\%), seborrhoeic dermatitis $(2.7 \%)$ and pityriasis alba (1.1\%).

Pigmentary disorders were the third ranking dermatosis (118 cases, 17.8\%) with vitiligo being the most common, in $8.3 \%$ of patients. The mean age of patients with vitiligo was 5.9 (SD 1.8) years. Segmental, acrofacial and halo nevi were the commonest presentation. The most frequent site of involvement was the head (58.2\%) followed by the trunk (29.1\%) and limbs (9.1\%). Other less common pigmentary dermatoses included post-inflammatory hypopigmentation (5.6\%) and postinflammatory hyperpigmentation (3.9\%).

Papulosquamous dermatoses were the fourth ranked type (94 cases, $14.2 \%)$. Among them, psoriasis was the most common (5.3\%). The mean age of patients with psoriasis was 7.3 (SD 2.5) years. The scalp were the most common initial site affected (28.6\%) followed by flexures of legs (17.1\%). Classical plaque psoriasis was the most frequent clinical presentation (62.8\%) followed by guttate psoriasis (14.3\%). Nail involvement was seen in $22.8 \%$ of patients in the form of pitting, ridging and discolouration. Other papulosquamous dermatoses involved lichen planus (3.9\%), pityriasis rosea (2.9\%), and pityriasis rubra pilaris $(2.1 \%)$. 


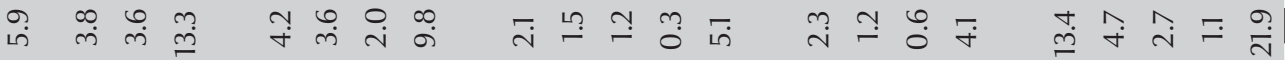

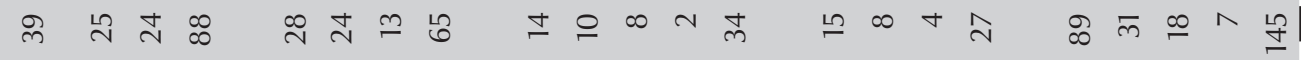

ॠ

$\frac{5}{\frac{5}{0}}$

: 


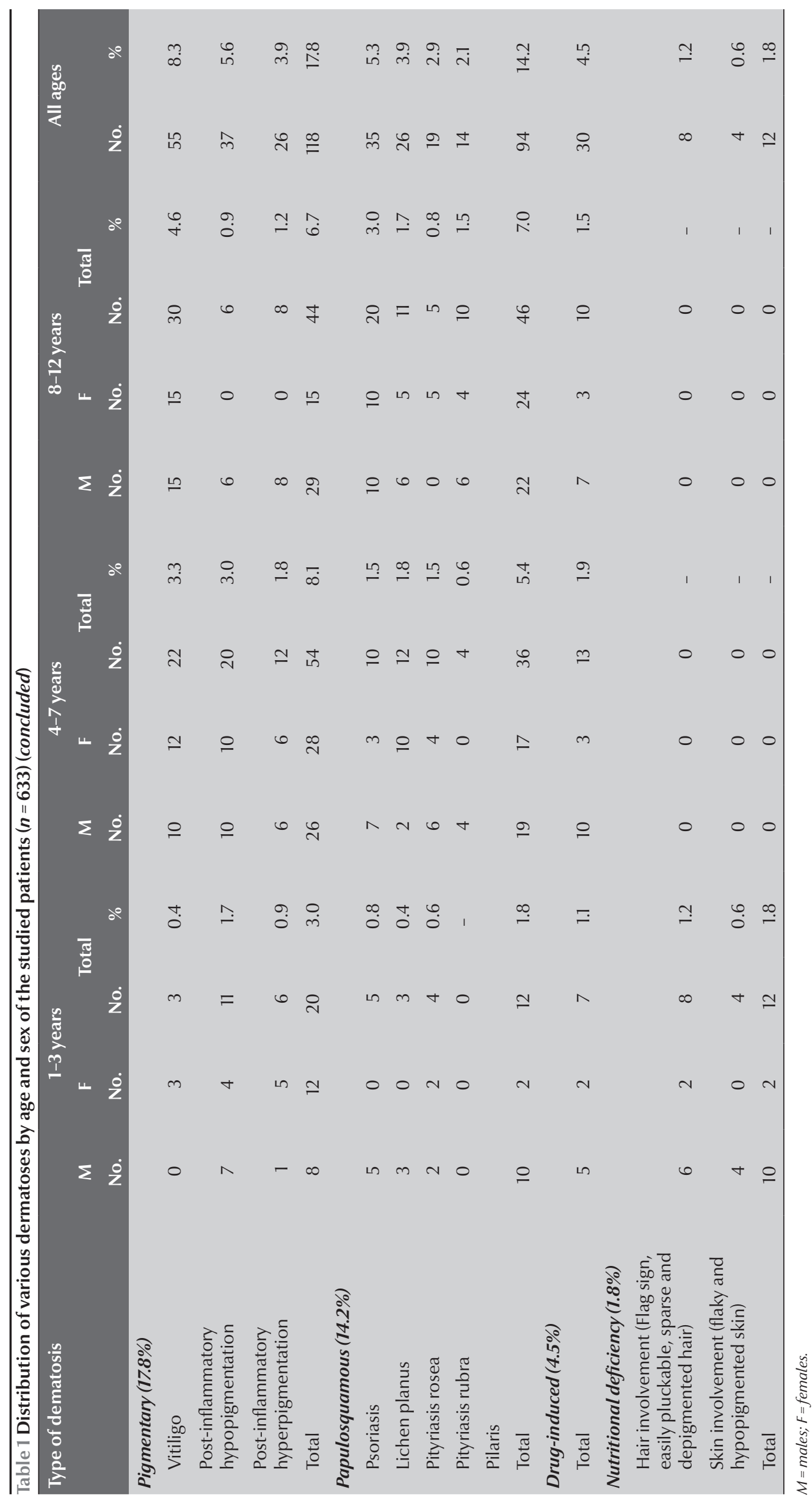


Drug-induced dermatoses ranked fifth (30 cases, $4.5 \%$ ). Penicillin derivatives, trimethoprim-sulfamethoxazole, cephalexin, erythromycin, and sodium valproate were the preponderant drugs causing adverse skin reactions. Their adverse skin effects varied from simple maculopapular rash to bullous lesions.

Nutritional deficiency disorders were the least common dermatoses. They were noticed in only $12(1.8 \%)$ children: 8 (1.2\%) marasmic children and $4(0.6 \%)$ with kwashiorkor.

A diverse group of unclassified dermatoses were categorized in a miscellaneous group (57 cases, 8.6\%). This included ulcer, trichotillomania, purpura, insect bite, alopecia areata, haemangioma, urticaria, keloid, miliaria and nevi.

No sex- or age-specific differences in dermatoses was recorded among the studied cases, except for a predominance of cases of nutritional deficiencyinduced dermatoses in the age group $1-3$ years, particularly infants.

\section{Discussion}

A significant percentage of the workload of general practitioners is dermatological [7]. It is necessary to know the epidemiological background of common skin diseases. Such study is important for improvement of treatment facilities as well as pharmaceutical industries and health planning [8].

The present study showed that infectious dermatoses were the predominant category (32.3\%), with a majority of cases being fungal infections (13.3\%). The common dermatophyte genera Trichophyton, Microsporum, and Epidermophyton are major causes of superficial fungal infections in children. These infections are typically acquired directly from contact with infected or human or animals or indirectly from exposure to contaminated soil or fomites [9]. Poor hygienic and sanitary conditions and lack of awareness and health services for the skin diseases probably contributed to the high prevalence of infectious dermatoses.

Eczematous dermatoses were diagnosed in $21.9 \%$ of patients. Atopic dermatitis was the predominant type (14.5\%). This is the most common chronic inflammatory skin disease of childhood and is increasing in prevalence throughout the world. Visits of children with atopic dermatitis to officebased physicians and hospital outpatient departments are increasing too [10]. Most patients with atopic dermatitis were below 8 years of age with the peak incidence in $0-3$ year age group.

Pigmentary dermatoses were detected in $17.8 \%$ of patients. Vitiligo, post-inflammatory hypopigmentation, and post-inflammatory hyperpigmentation were seen in $8.3 \%, 5.6 \%$ and $3.9 \%$ of patients respectively.

Papulosquamous dermatoses were noticed in $14.2 \%$ of patients. Among them, psoriasis was the most common (5.3\%), followed by lichen planus (3.9\%), pityriasis rosea $(2.9 \%)$, and pityriasis rubra pilaris $(2.1 \%)$.

It is well-known that various medicines are associated with adverse skin reactions [11]. The low prevalence of drug-induced dermatoses (4.5\%) noted in the present study might be attributed to the relative shortage of drugs in health care centres and hospitals on the one hand and the expense of obtaining them from private pharmacies on the other hand. The main offending drugs noted in the study were penicillin derivatives, trimethoprim-sulfamethoxoazole, cephalexin erythromycin and sodium valproate.

Nutritional disorders are often associated with various dermatoses [12]. Although malnutrition has been reported in nearly $28 \%$ of Iraqi children [13], the reported prevalence of nutritional deficiency dermatoses in the present study was small (1.8\%), namely marasmus (1.2\%) and kwashiorkor (0.6\%). This might be explained by parents worried about growth failure in malnourished children seeking nutritional rehabilitation in hospitals rather than dermatological consultation for skin lesions.

Various studies have shown important sex- and age-specific differences in paediatric predisposition and diagnosis of dermatoses. For example, a preponderance among girls has been noted for psoriasis [14], pityriasis rosea [15], pediculosis capitis [16], and lichen planus [17]. On the other hand, pediculosis capitis was found to be predominant in the age group 8-12 years [18], cutaneous tuberculosis in 10-14 years [19] and tinea capitis in 5-15 years [20]. However, the current study revealed no sex- or age-specific differences in the studied dermatoses except for a preponderance of cases of nutritional deficiency-induced dermatoses in the age group $1-3$ years, particularly infants. This generally seems consistent with data reported previously $[5,21]$.

It is noteworthy that Iraqi children have suffered physically, nutritionally and psychosocially by the consequences of the antecedent conflicts in Iraq [22]. Stressful life events are known to play an important role in the onset and aggravation of various dermatoses, namely psoriasis, vitiligo, alopecia aereata, lichen planus, atopic dermatitis [23-26]. In addition, the Iraqi health care system is still crippled by the conflicts in the country [27], which hinder the treatment of many health problems including dermatological ones.

In comparison with other studies, our data resembled to some extent that reported in developing countries. In an Ethiopian study [28], allergic skin diseases were most frequently found (55\%), followed by infections (33\%), and photodermatosis (8\%). Of the allergic skin diseases, atopic dermatitis was the most prevalent (47\%), followed by seborrhoeic dermatitis (17.4\%). In an Egyptian study [29], parasitic skin infestations had the highest prevalence rate $(27.4 \%)$, of which pediculosis capitis (19.4\%) was the commonest. Eczema/dermatitis had a prevalence 
of $19.8 \%$, with pityriasis alba forming the majority (13.5\%). Pigmentary disorders were $17.7 \%$, followed by fungal skin infections (16.2\%), then naevoid disorders (16.1\%), hair and scalp disorders $(12.07 \%)$, bacterial skin infections $(10.1 \%)$, sweat gland disorders (6.2\%) and acne vulgaris (5.4\%). In another Indian study [30], infections and infestations were the most common dermatoses (54.5\%) followed by dermatitis and eczema (8.6\%), pigmentary disorders (5.7\%), insect bite reaction (5.3\%) and hair and nail disorders (5.2\%). Pyodermas (47.13\%) and scabies $(30.6 \%)$ were the most common dermatoses due to infections and infestations. In a Yemeni study [31], the leading group of diseases was dermatitis and eczematous disorders, followed by infections and infestations (including cutaneous leishmaniasis and myceto$\mathrm{ma})$, and acne and acneiform disorders. In a Nigerian study [32], infectious and parasitic diseases accounted for $44.4 \%$ of cases, eczema, acne, papulosquamous, and pigmentary skin disorders were observed in $14.1 \%, 7.0 \%, 64 \%$, and $6.0 \%$ of cases respectively. In a study in Pakistan [33], infectious skin diseases were the commonest (60\%). Among the infections, fungal were maximum (20.6\%), followed by bacterial diseases (12\%). Eczemas constituted $21 \%$ of skin diseases and $6.4 \%$ children had congenital skin conditions. The relative similarity between the pattern of data in our study and those reported in the aforementioned developing countries might suggest a cumulative effect of various socioeconomic, nutritional and environmental factors [34].

The current study had some limitations. First, the collected data represented a cross-sectional study on paediatric dermatoses in a single dermatological clinic and was not representative of the whole country. Secondly the study would be more informative if a comparison were made with similar data published before. However, no nationwide studies on the whole pattern of paediatric dermatoses exist. Despite these limitations, the study can be regarded as a preliminary one and a step towards further elucidation of the issue in future studies.

In conclusion, paediatricians and dermatologists in Iraq need be aware about these prevailing dermatoses and be able to handle them properly. Epidemiological research to identify risk factors for different types of dermatoses is needed in order to plan for effective preventive measures to improve the health status of these children.

\section{Acknowledgements}

We would like to thank the staff of dermatological consultation outpatient clinic at Al-Kindy teaching hospital, Baghdad for their help in conducting this study.

\section{References}

1. Epidemiology and management of common skin diseases in children in developing countries. Geneva, World Health Organization, $2005(\mathrm{WHO} / \mathrm{FCH} / \mathrm{CAH} / 05.12$.)

2. Hay RJ et al. Wastage of family income on skin disease in Mexico. British Medical Journal, 1994, 309:848.

3. Basra MK, Finlay AY. The family impact of skin diseases: the Greater Patient concept. British Journal of Dermatology, 2007, 156:929-937.

4. Abdul Hussain HM. Morbidity rates of skin diseases in Baghdad city [diploma dissertation]. Baghdad, Iraq, Faculty of Medicine, University of Baghdad, 1987.

5. Khalifa KA et al. Prevalence of skin disorders among primaryschool children in Baghdad governorate, Iraq. Eastern Mediterranean Health Journal, 2010, 16:209-213.

6. Darmstadt GL, Sidbury R. The skin. In: Behrman RE, Kliegman $\mathrm{RM}$, Jenson $\mathrm{HB}$, eds. Nelson textbook of pediatrics, $17 \mathrm{th}$ ed. Philadelphia. Kliegman, 2004.

7. Milaković SB et al. Bolesti koze kao razlog cestih posjeta djece predskolske dobi lijecniku u primarnoj zdravstvenoj zastiti [Skin diseases as a reason for frequent preschool, primary healthcare attendance]. Acta Medica Croatica, 2007, 61:69-75.

8. Alakloby OM. Pattern of skin diseases in Eastern Saudi Arabia. Saudi Medical Journal, 2005, 26:1607-1610.

9. Andrews MD, Burns M. Common tinea infections in children. American Family Physician, 2008, 77:1415-1420.

10. Horii KA et al. Atopic dermatitis in children in the United States, 1997-2004: visit trends, patient and provider characteristics, and prescribing patterns. Pediatrics, 2007, 120:e527e534.
11. Raksha MP, Marfatia YS. Clinical study of cutaneous drug eruption in 200 patients. Indian Journal of Dermatology, Venereology and Leprology, 2008, 74:80.

12. Oumeish OY, Oumeish I. Nutritional skin problems in children. Clinics in Dermatology, 2003, 21:260-263.

13. Conflict in Iraq masks humanitarian crisis. Oxfam [press release], 30 July 2007 (http://www.oxfaminternational.org/en/, accessed 13 February 2012).

14. Seyhan M et al. Psoriasis in childhood and adolescence: evaluation of demographic and clinical features. Pediatrics International, 2006, 48:525-530.

15. Ayanlowo O, Akinkugbe A, Olumide $\mathrm{Y}$. The pityriasis rosea calendar: a 7 year review of seasonal variation, age and sex distribution. Nigerian Quarterly Journal of Hospital Medicine, 2010, 20:29-31.

16. Soultana $V$ et al. Prevalence of pediculosis capitis among schoolchildren in Greece and risk factors: a questionnaire survey. Pediatric Dermatology, 2009, 26:701-705.

17. Walton KE et al. Childhood lichen planus: demographics of a US population. Pediatric Dermatology, 2010, 27:34-38.

18. Buczek A et al. Pediculosis capitis among schoolchildren in urban and rural areas of eastern Poland. European Journal of Epidemiology, 2004, 19:491-495.

19. Kumar B et al. Childhood cutaneous tuberculosis: a study over 25 years from northern India. International Journal of Dermatology, 2001, 40:26-32.

20. Ali J, Yifru S, Woldeamanuel Y. Prevalence of tinea capitis and the causative agent among school children in Gondar, North West Ethiopia. Ethiopian Medical Journal, 2009, 47:261-269. 
21. Al-Rubaiy KK, Habib OS, Ebrahim S. Pattern of skin diseases among primary school children in Basrah, southern Iraq. Medical Journal of Basrah University, 2004, 1-2:40-42.

22. Al-Obaidi AK, Piachaud J. While adults battle, children suffer: future problems for Iraq. Journal of the Royal Society of Medicine, 2007, 100:394-395.

23. Naldi L et al. Family history of psoriasis, stressful life events, and recent infectious disease are risk factors for a first episode of acute guttate psoriasis: results of a case-control study. Journal of the American Academy of Dermatology, 2001, 44:433-438.

24. Manolache L, Benea V. Stress in patients with alopecia aereata and vitiligo. Journal of the European Academy of Dermatology and Venereology, 2007, 21:921-928.

25. Manolache L, Seceleanu-Petrescu D, Benea V. Lichen planus patients and stressful events. Journal of the European Academy of Dermatology and Venereology, 2008, 22:437-441.

26. Arndt J, Smith N, Tausk F. Stress and atopic dermatitis. Current Allergy and Asthma Reports, 2008, 8:312-317.

27. Dyer O. Iraqi healthcare system is still crippled five years after invasion, says report. British Medical Journal, 2008, 336:113.
28. Shibeshi D. Pattern of skin diseases at the Ethio-Swedish pediatric hospital, Addis Ababa, Ethiopia. Pediatric Dermatology, 2000, 17:357-359.

29. Abdel-Hafez K, Abdel-Aty MA, Hofny ER. Prevalence of skin diseases in rural areas of Assiut Governorate, Upper Egypt. International Journal of Dermatology, 2003, 42:887-892.

30. Sardana $\mathrm{K}$ et al. The spectrum of skin disease among Indian children. Pediatric Dermatology, 2009, 26:6-13.

31. Lal Khatri M. Spectrum of skin diseases in Yemen (Hajjah and adjacent region). International Journal of Dermatology, 2004, 43:580-585.

32. Onayemi O, Isezuo SA, Njoku CH. Prevalence of different skin conditions in an outpatient's setting in north-western Nigeria. International Journal of Dermatology, 2005, 44:7-11.

33. Yasmeen N, Khan MT. Spectrum of common childhood skin diseases: a single center experience. Journal of the Pakistan Medical Association, 2005, 55:60-63.

34. Morrone A. Poverty, health, and development in dermatology. International Journal of Dermatology, 2007, 46(Suppl. 2):1-9.

\section{Correction}

Seroprevalence of hepatitis B and C among barbers and their clients in the Rabat region of Morocco. I. Belbacha, I. Cherkaoui, M. Akrim, K.E. Dooley and R. El Aouad. Eastern Mediterranean Health Journal, 2011, 17(12):911-919. Reference 7 should read: Bhatti T. Prevalence and risk factors of hepatitis $B$ and $C$ among barbers and their regular clients in Hyderabad, Pakistan. In: Operational research in tropical and other communicable diseases. Final report summaries 2007-2008: results portfolio 4 small grants scheme. Cairo, World Health Organization Regional Office for the Eastern Mediterranean, 2010 (http://www.emro.who.int/dsaf/dsa1040.pdf). 